\title{
Synthesis of Polycyclic Dihydroindoles by Selective Decomposi- tion of Bis(1,2,3-triazoles) Mediated by Rhodium Catalysis
}

\author{
Sampad Jana, ${ }^{\mathrm{a}}$ Robby Vroemans, ${ }^{\mathrm{a}}$ and Wim Dehaen ${ }^{\mathrm{a}, *}$ \\ a Molecular Design and Synthesis, Department of Chemistry, KU Leuven, Celestijnenlaan 200F, B-3001 Leuven, Belgium \\ E-mail:wim.dehaen@kuleuven.be
}

Received: June 13, 2017; Revised: July 24, 2017; Published online: $\mathbf{\square}$ u, 0000

Supporting information for this article can be found under https://doi.org/10.1002/adsc.201700756.

\begin{abstract}
We report the selective decomposition of bis(1,2,3-triazoles) under rhodium(II) catalysis. The bis(1,2,3-triazoles) undergo an intramolecular transannulation reaction via an azavinylcarbene intermediate, resulting in the formation of polycyclic dihydroindoles containg a fused triazole ring.

Keywords: azavinylcarbenes; click chemistry; rhodium(II) catalysis; triazoles
\end{abstract}

Substituted indoles are encountered in a vast number of heterocyclic molecules with a wide range of applications ranging from medicinal to material chemistry. ${ }^{[1]}$ More specifically, 3,4-fused indoles and hapalindole alkaloid analogues are important pharmacophores found in Nature, such as dehydrobufotenine, chanoclavine, lysergic acid, and cyclavine (Figure 1) ${ }^{[2]}$ Generally, this type of fused indole can be synthesized only via multistep procedures. ${ }^{[2,3]}$ Therefore, the bio-

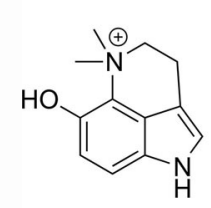

Dehydrobufotenine 1

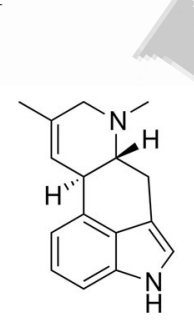

Chanoclavine-I

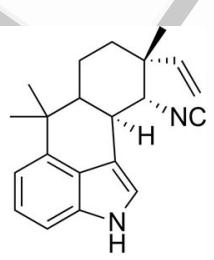

Hapalindole $\mathrm{H}$

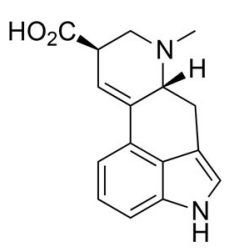

Lysergic acid

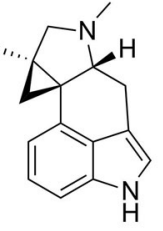

(-)-Cyclavine
Figure 1. Representative bioactive molecules with a 3,4fused indole core. logical properties of these types of fused heterocycles remain for the most part unexplored because of the difficulties in obtaining them in sufficient quantities. Hence, the development of atom economic one-step synthetic strategies towards 3,4-fused indoles is highly desirable.

In recent years, azavinylcarbenes derived from $N$ sulfonyl-1,2,3-triazoles have drawn considerable attention in the chemical community as a means towards the synthesis of various heterocycles which are otherwise very difficult to prepare. ${ }^{[4,5,6]} 1,2,3$-Triazoles are known to be very stable heterocycles, however they can be decomposed to azavinylcarbenes by using appropriate substituents on the 1,2,3-triazole ring and a transition metal catalyst. In 2007, Gevorgyan was first to point out that 1,2,3-triazoles could be cleaved by transition metal catalysis to azavinylcarbene species, which was further used in various transformation. ${ }^{[4,5,6]}$ Since then, a vast number of synthetic strategies have been discovered including transannulation, cyclopropanation, dehydrogenative rearrangements, $\mathrm{C}-\mathrm{H}$ bond insertion, ring expansion, and ylide formation, in which 1-sulfonyl-1,2,3-triazoles have been used as a carbene precursor. ${ }^{[4,5,6]}$. We have been working on the development of various synthetic strategies towards the synthesis of functionalized 1,2,3-triazoles. ${ }^{[7]} \mathrm{Re}$ cently, we have reported a novel methodology towards the synthesis of propargyl-substituted 1,2,3-triazoles, and further functionalization of these triazoles via $\mathrm{Cu}(\mathrm{I})$-catalyzed click reactions resulted in the formation of unique N,C-linked bis(1,2,3-triazoles). ${ }^{[7 a]}$

In 2014 Murakami et al. reported an intramolecular dearomatizing annulation reaction of 4-(3-arylpropyl)-1,2,3-triazoles furnishing dihydroindole skeletons. ${ }^{[4 k]}$ Inspired by this report, we have anticipated that this reaction could be applied to the N,C-linked bis(1,2,3-triazoles) bearing the appropriate substituents (Scheme 1). The bis(1,2,3-triazole) 1a, has been synthesized from $N$-propargyl-5-phenyltriazole with tosyl azide in the presence of copper(I) thiophene-2carboxylate $(\mathrm{CuTc})$ catalyst. As we had hoped, our in- 
a) previous work: decomposition of triazole into azavinylcarbene

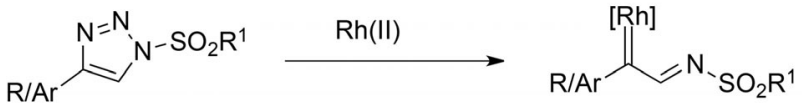

b) this work: selective decomposition of triazole into azavinylcarbene

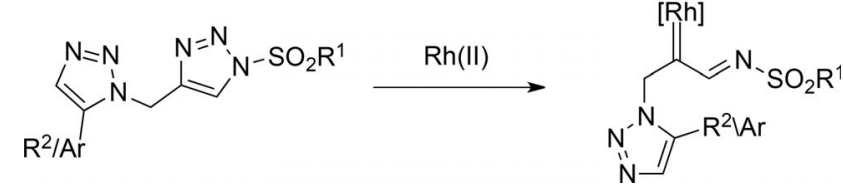

Scheme 1. Decomposition of triazole into azavinylcarbene.

itial trial with 1a in the presence of $\mathrm{Rh}(\mathrm{II})$ leads to selective decomposition of the 1,4-disubstituted 1,2,3triazole core, leading to a 3,4-fused dihydroindole $\mathbf{2 a}$ via an intramolecular [3+2]-annulation reaction. To the best of our knowledge, this is the first example of a selective decomposition of bis(1,2,3-triazoles) into azavinylcarbenes in the presence of a rhodium catalyst.

After getting this promising result, we started to optimize this novel annulation reaction (Table 1). Triazole 1a was treated with a catalytic amount of $\mathrm{Rh}_{2}(\mathrm{OAc})_{4}$ in dry DCE at $80^{\circ} \mathrm{C}$ under a nitrogen atmosphere, and the desired fused indole $2 \mathbf{a}$ was obtained in $43 \%$ yield after $12 \mathrm{~h}$. An increase in yield

Table 1. Optimization of the reaction conditions. ${ }^{[\mathrm{a}]}$

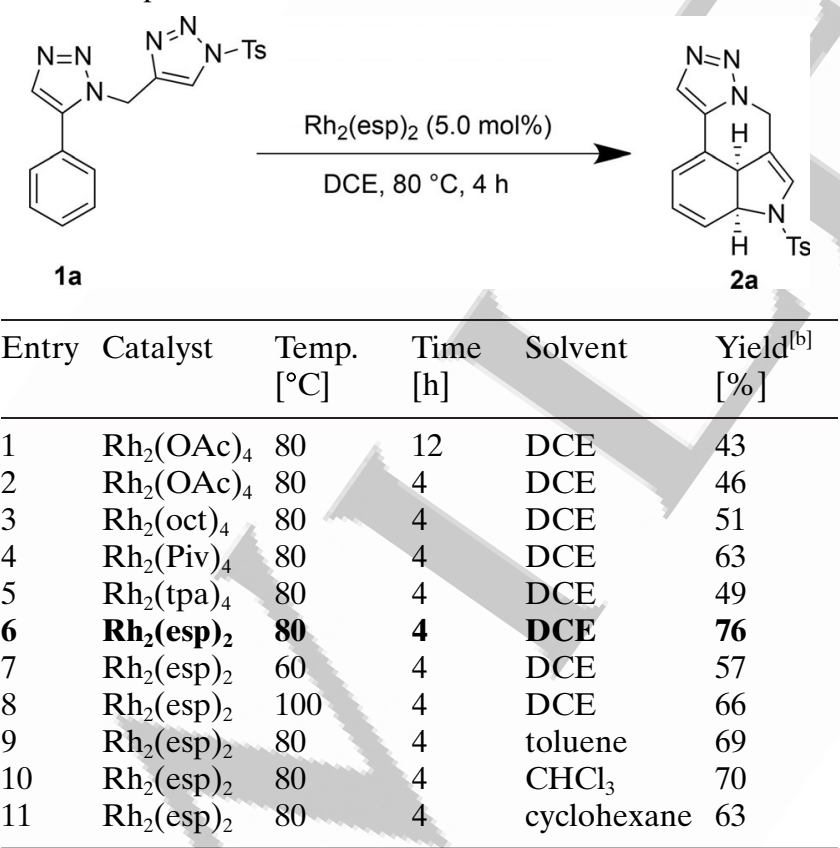

a] All reactions were conducted on a $0.26 \mathrm{mmol}$ scale in $4 \mathrm{~mL}$ solvent with $5 \mathrm{~mol} \%$ catalyst under an $\mathrm{N}_{2}$ atmosphere.

[b] Isolated yield. $\quad \mathrm{Rh}_{2}(\mathrm{tpa})_{4=} \mathrm{Rh}_{2}$ (triphenylacetate $)_{4}$, $\mathrm{Rh}_{2}(\mathrm{esp})_{2}=$ bis[rhodium $\left(\alpha, \alpha, \alpha^{\prime}, \alpha^{\prime}\right.$-tetramethyl-1,3-benzenedipropionic acid)]. was observed when the reaction time was reduced to $4 \mathrm{~h}$. Next, changing the catalyst from $\mathrm{Rh}_{2}(\mathrm{OAc})_{4}$ to $\mathrm{Rh}_{2}(\mathrm{esp})_{2}$ resulted in a significant increase in yield under the same conditions. Other catalysts, such as $\mathrm{Rh}_{2}(\text { oct })_{4}$ used by Murakami et al. ${ }^{[4 \mathrm{k}]} \mathrm{Rh}_{2}(\mathrm{Piv})_{4}$, and $\mathrm{Rh}_{2}(\text { tpa })_{4}$ gave no better result. It was found that the yield decreased if the reaction was carried out at a lower or a higher temperature than $80^{\circ} \mathrm{C}$. Also, changing the solvent to toluene, $\mathrm{CHCl}_{3}$ and cyclohexane resulted in slightly lower yields.

With the optimized conditions in hand, we started to investigate the role of the sulfonyl group substituents (Scheme 2). It was found that neither electrondonating or electron-withdrawing groups on the phenylsulfonyl ring had a significant effect on the outcome of the reaction ( $\mathbf{2 b}$ and $\mathbf{2 c}$ ). Next, the substitution effect on the 5-aryl ring was investigated (Scheme 2). Electron-donating groups such as $\mathrm{Me}$ (2d) and OMe (2e) at the 4- position resulted in slightly lower yields, whereas an electron-withdrawing
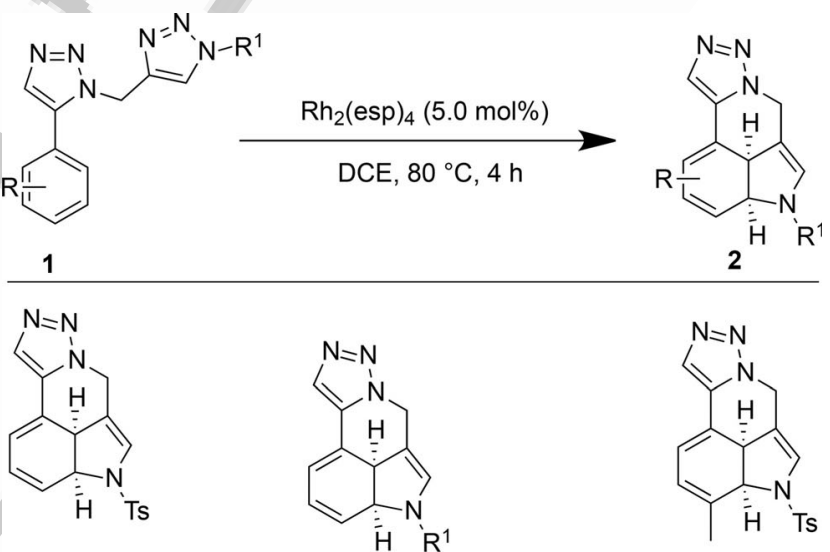

$2 a, 76 \%$

2b, $72 \%, \mathrm{R}^{1}=-\mathrm{SO}_{2}-\mathrm{C}_{6} \mathrm{H}_{4}-p-\mathrm{OMe}$

2d, $72 \%$

2c, $74 \%, \mathrm{R}^{1}=-\mathrm{SO}_{2}-\mathrm{C}_{6} \mathrm{H}_{4}-p-\mathrm{CF}_{3}$
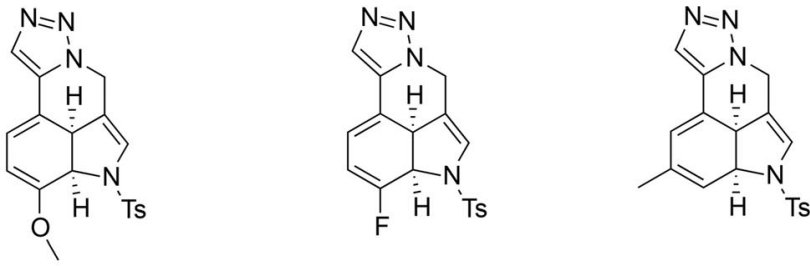

$2 e, 69 \%$

2f, $81 \%$

$2 \mathrm{~g}, 71 \%$
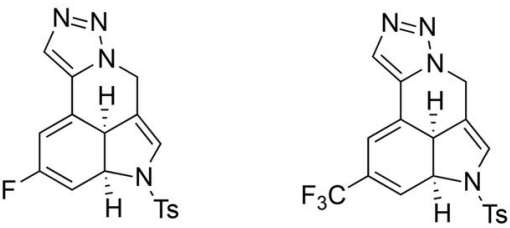

$2 i, 78 \%$

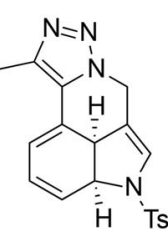

$2 \mathrm{j}, 73 \%$ 2h, $86 \%$

Scheme 2. Scope of the dearomatizing trans annulation reaction of bis(1,2,3-triazoles). General conditions: 1 $(0.23 \mathrm{mmol})$, and $\mathrm{Rh}_{2}(\mathrm{esp})_{2}(0.012 \mathrm{mmol})$, in DCE $(4 \mathrm{~mL})$ at $80^{\circ} \mathrm{C}$ for $4 \mathrm{~h}$, unless otherwise noted. 
group such as $\mathrm{F}(\mathbf{2 f})$ at the para position resulted in an increased yield. Similar trends were observed in the case of the meta isomers. For instance, meta-F (2h) and meta- $\mathrm{CF}_{3}$ (2i) substrates afforded excellent yields as compared to the meta-Me (2g) counterpart.

In order to prove the generality of this reaction, in addition to the transannulation reaction onto different substituted phenyl groups, the use of heterocyclic dibenzofuran was also investigated (Scheme 3). Substrate 1k underwent $\mathrm{Rh}(\mathrm{II})$-catalyzed intramolecular cyclization to give the corresponding polyheterocyclic product $\mathbf{2 k}$ in good yield.

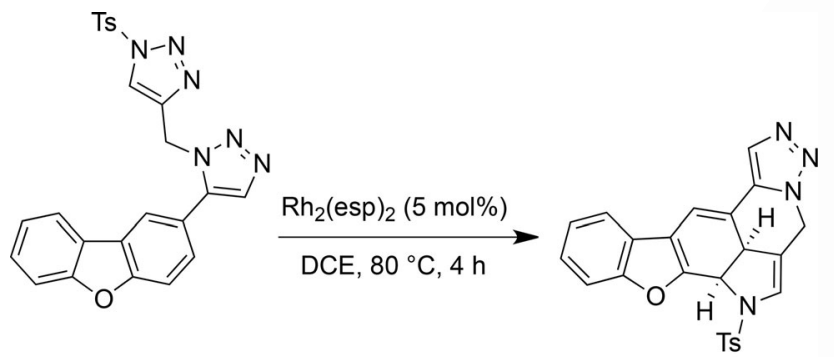

$1 \mathrm{k}$

2k, $63 \%$

Scheme 3. Use of benzofuran in the transannulation reaction towards $\mathbf{2 k}$.

3,4-Fused indole alkaloid analogues are interesting pharmacophores which could be accessible via oxidative aromatization of dihydroindole. Similar to Murakami et al. ${ }^{[4 k]}$ the oxidation reaction of 3,4-dihydroindole 2a was carried out with $\mathrm{MnO}_{2}$. This afforded the triazole-fused alkaloid analogue $\mathbf{3}$ in excellent yield (Scheme 4).

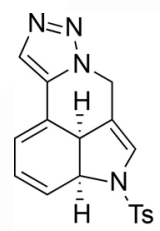

$2 a$

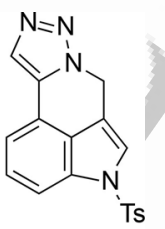

$3,89 \%$
Scheme 4. Formation of fused indole derivatives.

The synthetic utility of the $\mathrm{Rh}(\mathrm{II})$-catalyzed selective 1,2,3-triazole decomposition and annulation reaction was further exemplified by a one-pot synthesis of 3,4-fused dihydroindole 2a starting from propargyl triazole 4 in moderate yield (Scheme 5). Thus, in this way the interesting 1,2,3-triazole-derived (dihydro)indole alkaloid analogues are accessible in a few reaction steps.

A sequential one-pot synthesis of fused indole $\mathbf{3}$ was also carried out starting from bis(1,2,3-triazoles)

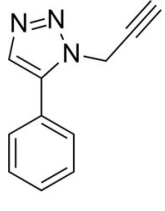

4
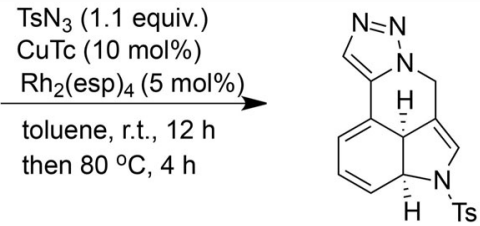

$2 a, 48 \%$
Scheme 5. One-pot procedure starting from propargyl triazoles.

1a. A mixture of bis(1,2,3-triazole) $\mathbf{1 a}$ and $\mathrm{Rh}_{2}(\mathrm{esp})_{2}$ was heated at $80^{\circ} \mathrm{C}$ in DCE for $4 \mathrm{~h}$ to form the dihydroindole. Subsequently, $\mathrm{MnO}_{2}$ was added to the same reaction vessel, and the mixture was further stirred at $80^{\circ} \mathrm{C}$ for $24 \mathrm{~h}$ to afford the fused indole of bis(1,2,3-triazole) $\mathbf{3}$ in good yield. Thus the sequential one-pot reaction provides an easy access to triazolefused indole $\mathbf{3}$ in good yield (Scheme 6).

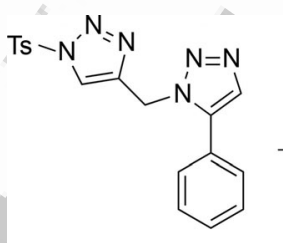

$1 \mathrm{a}$

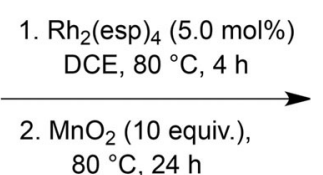

$80{ }^{\circ} \mathrm{C}, 24 \mathrm{~h}$

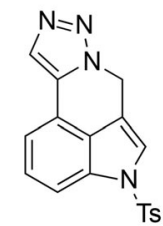

$3,66 \%$
Scheme 6. One-pot procedure to access triazole-fused indoles from bis(1,2,3-triazoles).

A reaction mechanism is postulated on the basis of the previous literature reports ${ }^{[4-6]}$ (Scheme 7). Triazole $\mathbf{1 a}$ is in equilibrium with ring-chain tautomer $\alpha$-diazo imine I, which subsequently reacts with $\mathrm{Rh}(\mathrm{II})$ affording $\alpha$-imino rhodium carbene complex II and releases molecular dinitrogen. Then, intramolecular nucleophilic attack occurs of the phenyl at the electrophilic carbene center in a 6-exo mode to generate zwitterionic species III. In a final step, the anionic rhodium of III undergoes elimination which drives the final cyclization step, leading to final product $\mathbf{2 a}$ and regenerating the $\mathrm{Rh}$ (II)-catalytic species.

In conclusion, we have disclosed an unprecedented selective decomposition of bis(1,2,3-triazoles) by a $\mathrm{Rh}(\mathrm{II})$-catalyzed [3+2]-intramolecular annulation reaction which leads to the formation of 3,4-fused indoles. Extension of this protocol to heterocycles led to interesting polyfused 1,2,3-triazole derivatives. This protocol presents a simple, one-step, and atom economic efficient method for the synthesis of 1,2,3-triazole-fused dihydroindoles and indoles, which could so far not be synthesized by other means. Further applications of these products in medicinal chemistry are in progress and will be reported in due course. 


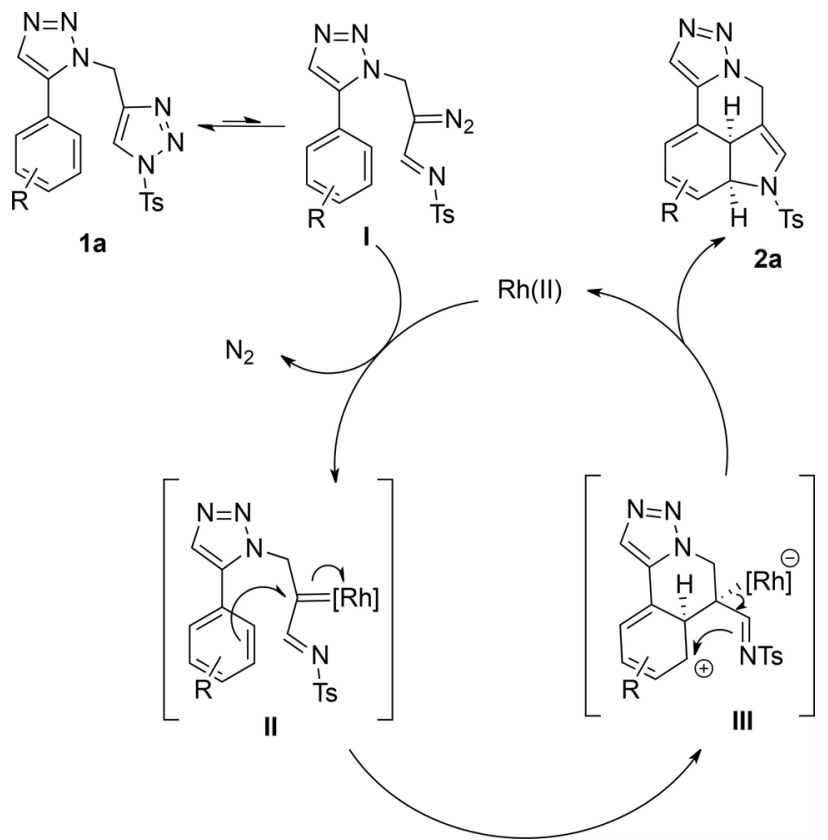

Scheme 7. Proposed reaction mechanism.

\section{Experimental Section}

\section{General Procedure for the Preparation of Bis- triazoles}

A flame-dried tube was charged with the appropriate propargyl triazole $(0.66 \mathrm{mmol}), \mathrm{CuTc}(0.06 \mathrm{mmol})$, and tosyl azide $(0.73 \mathrm{mmol})$ in dry toluene $(2 \mathrm{~mL})$ under an $\mathrm{N}_{2}$ atmosphere. The resultant mixture was heated at $60^{\circ} \mathrm{C}$ for $3 \mathrm{~h}$. After consumption of the starting material as apparent from TLC analysis, the crude reaction mixture was concentrated under vacuum, and the product was isolated by flash column chromatography (EtOAc:heptane 1:1) to afford the pure product.

\section{Typical Procedure for the Oxidative Aromatization Reaction}

A flame-dried reaction tube was charged with dihydroindole 2a (100 mg, $0.284 \mathrm{mmol})$ and $\mathrm{MnO}_{2}(123 \mathrm{mg}, 1.419 \mathrm{mmol})$ in DCE $(2 \mathrm{~mL})$. The reaction mixture was then heated at $80^{\circ} \mathrm{C}$ for $24 \mathrm{~h}$. After the completion of the reaction, the solvent was evaporated under vacuum. The crude reaction mixture was then directly purified by flash column chromatography (ACN: DCM 1:20) to afford fused indole 4 as an off-white solid; yield: $79 \mathrm{mg}(89 \%)$

\section{Acknowledgements}

We thank the Erasmus Mundus Lot 13, Euro-India fellowship for the doctoral funding to S.J. The Fonds Wetenschappelijk Onderzoek - Vlaanderen (FWO) (1S13516N) is acknowledged for the doctoral fellowship to R.V. Mass spec- trometry was done with the support of the Hercules Foundation of the Flemish Government (Grant 20100225-7).

\section{References}

[1] a) J. Pina, J. S. Seixas de Melo, A. Eckert, U. Scherf, J. Mater. Chem. A 2015, 3, 6373-6382; b) S. Castelar, P. Romero, J.-L. Serrano, J. Barberá, M. Marcos, RSC Adv. 2015, 5, 65932-65941; c) N. K. Kaushik, N. Kaushik, P. Attri, N. Kumar, C. H. Kim, A. K. Verma, E. H. Choi, Molecules 2013, 18, 6620-6662; d) S. M. Bronner, G. Y. J. Im, N. K. Garg, Heterocycles in Natural Product Synthesis, Wiley-VCH, 2011, pp221-265.

[2] a) F. Maerki, A. V. Robertson, B. Witkop, J. Am. Chem. Soc. 1961, 83, 3341-3342; b) H. H. Pertz, H.-C. Milhahn, E. Eich, J. Med. Chem. 1999, 42, 659-668; c) D. Jakubczyk, L. Caputi, C. E. M. Stevenson, D. M. Lawson, S. E. O'Connor, D. S. Goodsell, A. J. Olson, H. McWilliam, M. Remmert, J. Söding, J. D. Thompson, D. G. Higgins, Chem. Commun. 2016, 52, 14306-14309; d) D. Jakubczyk, L. Caputi, A. Hatsch, C. A. F. Nielsen, M. Diefenbacher, J. Klein, A. Molt, H. Schröder, J. Z. Cheng, M. Naesby, S. E. O'Connor, Angew. Chem. 2015, \#\#, \#\#\#\#-\#\#\#; Angew. Chem. Int. Ed. 2015, 54, 5117-5121; e) S. Li, A. N. Lowell, F. Yu, A. Raveh, S. A. Newmister, N. Bair, J. M. Schaub, R. M. Williams, D. H. Sherman, J. Am. Chem. Soc. 2015, 137, 15366-15369.

[3] a) Y. Yokoyama, K. Kondo, M. Mltsuhashl, Y. kama, Tetrahedron Lett. 1996, 37, 9309-9312; b) S. Liras, C. L. Lynch, A. M. Fryer, B. T. Vu, S. F. Martin, J. Am. Chem. Soc. 2001, 123, 5918-5918; c) A. J. Peat, S. L. Buchwald, J. Am. Chem. Soc. 1996, 118, 1028-1030; d) J. E. Spangler, H. M. Davies, J. Am. Chem. Soc. 2013, 135, 68026805.

[4] a) S. Chuprakov, F. W. Hwang, V. Gevorgyan, Angew. Chem. 2007, \#\#, \#\#\#\#\#\#\#\#; Angew. Chem. Int. Ed. 2007, 46, 4757-4759; b) N. Grimster, L. Zhang, V. V. Fokin, J. Am. Chem. Soc. 2010, 132, 2510-2511; c) S. Chuprakov, S. W. Kwok, L. Zhang, L. Lercher, V. V. Fokin, J. Am. Chem. Soc. 2009, 131, 18034-18035; d) B. T. Parr, H. M. L. Davies, Angew. Chem. 2013, \#\#, \#\#\#\#\#\#\#; Angew. Chem. Int. Ed. 2013, 52, 10044-10047; e) S. Chuprakov, B. T. Worrell, N. Selander, R. K. Sit, V. V. Fokin, J. Am. Chem. Soc. 2014, 136, 195-202; f) N. Selander, B. T. Worrell, V. V. Fokin, Angew. Chem. 2012, \#\#, \#\#\#\#\#\#\#; Angew. Chem. Int. Ed. 2012, 51, 1305413057; g) J. M. Yang, C. Z. Zhu, X. Y. Tang, M. Shi, Angew. Chem. 2014, \#\#, \#\#\#\#\#\#\#; Angew. Chem. Int. Ed. 2014, 53, 5142-5146; h) B. T. Parr, S. A. Green, H. M. L. Davies J. Am. Chem. Soc. 2013, 135, 47164718; i) K. Chen, Z. Z. Zhu, Y. S. Zhang, X. Y. Tang, M. Shi, Angew. Chem. 2014, \#\#, \#\#\#\#\#\#\#\#; Angew. Chem. Int. Ed. 2014, 53, 6645-6649; j) E. E. Schultz, V. N. G. Lindsay, R. Sarpong, Angew. Chem. 2014, \#\#, \#\#\#-\#\#\#; Angew. Chem. Int. Ed. 2014, 53, 9904-9908; k) T. Miura, Y. Funakoshi, M. Murakami, J. Am. Chem. Soc. 2014, 136, 2272-2275; 1) H.-D. Xu, Z.-H. Jia, K. Xu, H. Zhou, M.-H. Shen, Org. Lett. 2015, 17, 66-69.

[5] a) A. V. Gulevich, V. Gevorgyan, Angew. Chem. 2013, \#\#, \#\#\#\#\#\#\#; Angew. Chem. Int. Ed. 2013, 125, 14111413; b) S. W. Kwok, L. Zhang, N. P. Grimster, V. V. 
Fokin, Angew. Chem. 2014, \#\#, \#\#\#\#-\#\#\#; Angew. Chem. Int. Ed. 2014, 53, 3452-3456; c) B. T. Parr, S. A. Green, H. M. L. Davies, J. Am. Chem. Soc. 2013, 135, 4716-4718; d) S. W. Kwok, L. Zhang, N. P. Grimster, V. V. Fokin, Angew. Chem. 2014, \#\#, \#\#\#-\#\#\#\#; Angew. Chem. Int. Ed. Engl. 2014, 53, 3452-3456; e) Y. Shi, A. V. Gulevich, V. Gevorgyan, Angew. Chem. 2014, \#\#, \#\#\#\#\#\#\#; Angew. Chem. Int. Ed. 2014, 53, 1419114195; f) R. Panish, R. Selvaraj, J. M. Fox, Org. Lett. 2015, 17, 3978-3981; g) J. S. Alford, J. E. Spangler, H. M. L. Davies, J. Am. Chem. Soc. 2013, 135, 11712 11715 ; h) Y. O. Ko, H. J. Jeon, D. J. Jung, U. B. Kim, S. Lee, Org. Lett. 2016, 18, 6432-6435; i) T. Miura, Y. Funakoshi, T. Tanaka, M. Murakami, Org. Lett. 2014, 16, 2760-2763; j) F. Medina, C. Besnard, J. Lacour, Org. Lett. 2014, 16, 3232-3235; k) E. E. Schultz, R. Sarpong, J. Am. Chem. Soc. 2013, 135, 4696-4699; 1) H. Shang, Y. Wang, Y. Tian, J. Feng, Y. Tang, Angew. Chem. 2014, \#\#, \#\#\#\#\#\#\#\#; Angew. Chem. Int. Ed. 2014, 53, 5662-5666; m) Y. Yang, M. B. Zhou, X. H. Ouyang, R. Pi, R. J. Song, J. H. Li, Angew. Chem. 2015, \#\#, \#\#\#\#\#\#\#\#;
Angew. Chem. Int. Ed. 2015, 54, 6595-6599; n) T. Miura, M. Yamauchi, M. Murakami, Chem. Commun. 2009, 147, 1470-1471; o) R. Sun, Y. Jiang, X.-Y. Tang, M. Shi, Chem. Eur. J. 2016, 22, 5727-5733; p) S. Chuprakov, B. T. Worrell, N. Selander, R. K. Sit, V. V. Fokin, J. Am. Chem. Soc. 2014, 136, 195-202.

[6] For reviews: a) H. M. L. Davies, J. S. Alford, Chem. Soc. Rev. 2014, 43, 5151; b) A. DeAngelis, R. Panish, J. M. Fox, Acc. Chem. Res. 2016, 49, 115-127.

[7] a) S. Jana, J. Thomas, W. Dehaen, J. Org. Chem. 2016, 81, 12426-12432; b) J. Thomas, S. Jana, J. John, S. Liekens, W. Dehaen, Chem. Commun. 2015, 52, 2885-2888; c) J. Thomas, S. Jana, S. Liekens, W. Dehaen, Chem. Commun. 2016, 52, 9236-9239; d) S. Jana, S. Iram, J. Thomas, M. Hayat, C. Pannecouque, W. Dehaen, Molecules. 2017, 22, 303; e) S. Jana, S. Iram, J. Thomas, S. Liekens, W. Dehaen, Bioorg. Med. Chem. 2017, 25, 3671-3676; f) J. Thomas, J. John, N. Parekh, W. Dehaen, Angew. Chem. 2014, \#\#, \#\#\#\#\#\#\#; Angew. Chem. Int. Ed. 2014, 126, 10319-10323; g) J. John, J. Thomas, W. Dehaen, Chem. Commun. 2015, 51, 10797-10806. 
6 Synthesis of Polycyclic Dihydroindoles by Selective Decomposition of Bis(1,2,3-triazoles) Mediated by Rhodium Catalysis

Adv. Synth. Catal. 2017, 359, 1-6
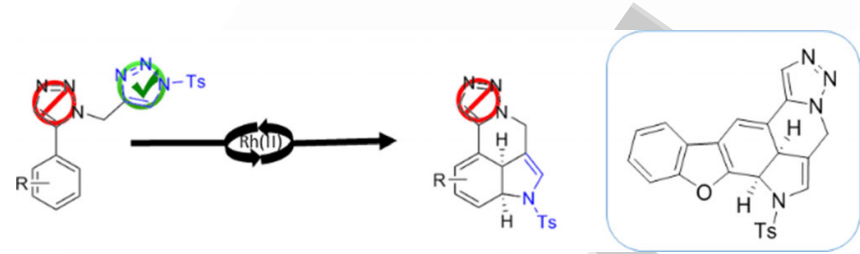

Sampad Jana, Robby Vroemans, Wim Dehaen* 